\title{
Analysis of density and mechanical properties of high velocity compacted iron powder
}

\author{
Jianzhong WANG, Haiqing YIN and Xuanhui $Q U^{*}$
}

State Key Laboratory for Advanced Metals and Materials, School of Materials Science and Engineering, University of Science and Technology Beijing, Beijing 100083, China

Manuscript received 9 January 2009; in revised form 16 March 2009

\begin{abstract}
A new method for producing higher density PM parts, high velocity compaction (HVC), was presented in the paper. Using water atomized pure iron powder without lubricant admixed as the staring material, ring samples were compacted by the technique. Scanning electron microscopy (SEM) and a computer controlled universal testing machine were used to investigate the morphologies and the mechanical properties of samples, respectively. The relationships among the impact velocity, the green density, the sintered density, the bending strength and the tensile strength were discussed. The results show that with increasing impact velocity, the green density and the bending strength increase gradually, so the sintered density does. In addition, the tensile strength of sintered material is improved continuously with the sintered density enhancing. In the study, the sintered density of $7.545 \mathrm{~g} / \mathrm{cm}^{3}$ and the tensile strength of $190 \mathrm{MPa}$ are achieved at the optimal impact velocity of $9.8 \mathrm{~m} / \mathrm{s}$.

KEY WORDS Powder metallurgy; High velocity compaction; Density; Mechanical properties; Iron powder
\end{abstract}

\section{Introduction}

Some metal parts, such as bearings and filters, require high porosity to retain oil, but in most cases the highest practical density is indispensable for strength, ductility and surface quality, etc. In addition, green compacts with higher density are beneficial to transport before sintering and have better dimensional stability during sintering than lower density parts $^{[1]}$. In recent years, there are a number of methods for preparing high density components, such as warm compaction, double compaction (P2S2), explosive compaction, powder forging and high velocity compaction (HVC). Warm compaction method depends on a special lubricant, but the lubricant used may reduce the sintered density and decrease the mechanical properties of parts. Double compaction technology has been established for many years, but is limited for high costs. Explosive compaction technique is limited owing to the explosive used and the low productivity. For powder forging, the surface finish and tool economy are inferior compared to other mentioned processes above. So for many high

\footnotetext{
*Corresponding author. Professor, PhD; Tel.: +861062332700; Fax: +86 1062334311.

E-mail address: quxh@mater.ustb.edu.cn (Xuanhui QU)
}

DOI: $10.1016 / \mathrm{S} 1006-7191(08) 60122-2$ 
performance applications the HVC process is the most attractive from cost/performance point of view ${ }^{[2,3]}$.

The HVC technique is similar to conventional process but consists in accelerating a hammer and inputting impact energy instead of force. The hammer strikes the upper punch with a given kinetic energy and the stress increases in a very short time ${ }^{[4]}$. The press enables to achieve densification in a short time, less than $0.3 \mathrm{~s}$, shorter than conventional compaction but longer than explosive pressing $(0.001 \mathrm{~s})^{[5]}$. Advantages of the process are high density, uniform density distribution, low ejection force and low springback, etc., but only can single-level parts be produced and the die is expensive ${ }^{[6]}$.

Recently, iron based powders with lubricant added were investigated using $\mathrm{HVC}^{[5,7,8]}$ and a comparative study of conventional pressing and HVC was done ${ }^{[8,9]}$. Although the lubricant admixed can reduce inter-particle friction, its most important role is to overcome particle-die wall friction ${ }^{[10,11]}$. Furthermore, no lubricant can burn off substantially during sintering, whilst leaving ashes inside the part. So, it hinders the diffusion process during sintering. In the paper, iron powder without lubricant added was pressed by HVC, and then the density and the mechanical properties of parts were discussed.

\section{Experimental Procedure}

Water atomized pure iron powder without lubricant admixed as the starting materials was compacted adopting HVC method. Characteristics and image of the powder were shown in Table 1 and Fig.1, respectively. Ring parts, with outer and inner diameters of $60 \mathrm{~mm}$ and $30 \mathrm{~mm}$, respectively, were prepared as shown in Fig.2. The mass of filled powder was $100 \mathrm{~g}$ for each pressing and three specimens were produced at each impact velocity.

The HVC device and the schematic illustration of compaction process were shown in Fig.3a and Fig.3b, respectively. The die was equipped on the tool adapter, whereas the

Table 1 Characteristics of water atomized pure iron powder

\begin{tabular}{|c|c|c|c|c|c|c|}
\hline \multirow{2}{*}{$\begin{array}{l}\text { Apparent density } \\
\left(\mathrm{g} / \mathrm{cm}^{3}\right)\end{array}$} & \multirow{2}{*}{$\begin{array}{l}\text { Tap density } \\
\left(\mathrm{g} / \mathrm{cm}^{3}\right)\end{array}$} & \multirow{2}{*}{$\begin{array}{l}\text { Flowability } \\
\text { (s/50 g) }\end{array}$} & \multicolumn{4}{|c|}{ Particle size distribution (volume pct) } \\
\hline & & & $<46 \mu \mathrm{m}$ & $46-76 \mu \mathrm{m}$ & $76-150 \mu \mathrm{m}$ & $>150 \mu \mathrm{m}$ \\
\hline 3.10 & 3.92 & 25.4 & 35.1 & 33.5 & 25.3 & 6.1 \\
\hline
\end{tabular}

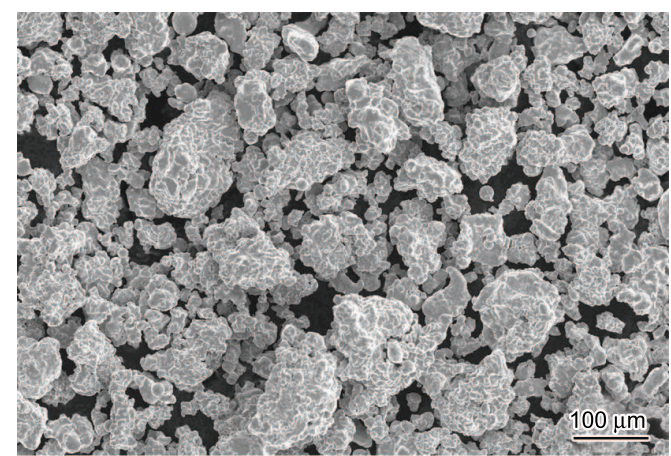

Fig.1 Image of water atomized pure iron powder.

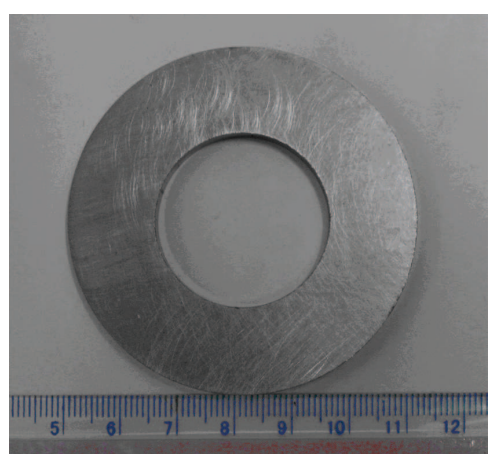

Fig.2 Ring sample. 


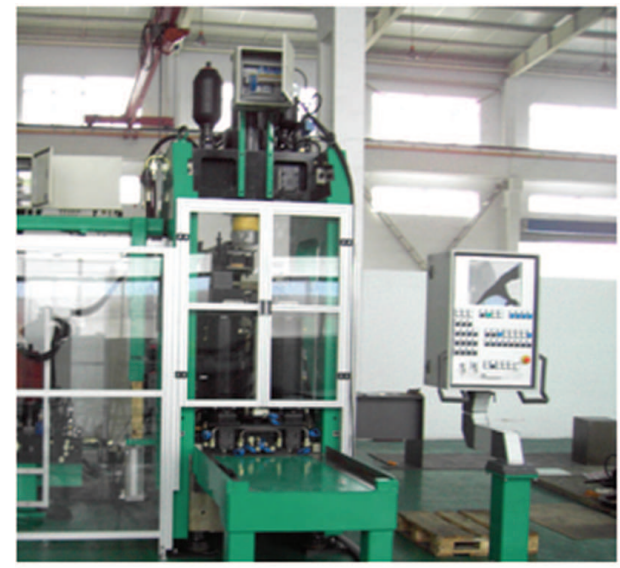

(a)

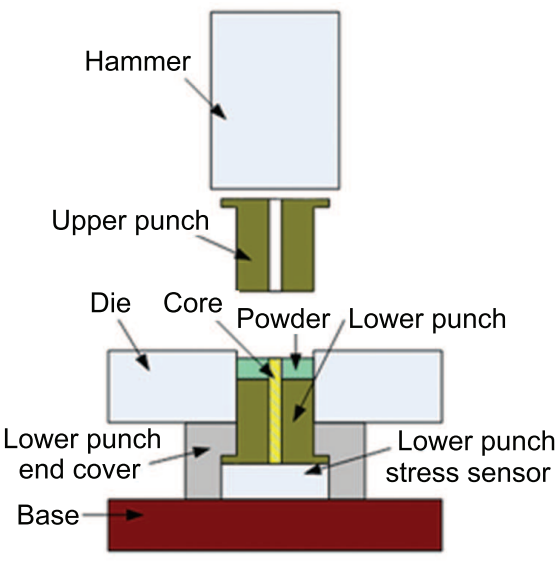

(b)

Fig.3 High velocity compaction machine (a) and schematic illustration of compaction process (b).

lower punch was mechanically fixed. The HVC process has the same steps as conventional compaction, i.e. die filling, pre-compacting, compacting and ejecting sample from die, and the tool design is similar. During the compaction, the equipment is controlled by a computer and the impact velocity can be varied by adjusting the stroke length. The die is lubricated with Zn-stearate and a pre-compacting of $33 \mathrm{MPa}$ is applied before each compaction.

Sintering has been performed using a laboratory tubular furnace in pure hydrogen protective atmosphere at $1200{ }^{\circ} \mathrm{C}$ for $120 \mathrm{~min}$, and then cooling at the furnace. Green density is measured using Archimedes' law and cross-section morphologies of samples are observed by scanning electron microscopy (SEM). A computer controlled universal testing machine is used to measure the bending strength of green compacts and the tensile strength of sintered parts.

The impact velocity can be calculated according to Eq.(1):

$$
v=\sqrt{\frac{2 F h}{m}}
$$

where $v$ is the impact velocity, $m / s ; F$ is the hydraulic oil pressure applied on the hammer, $\mathrm{kN} ; h$ is the stroke length, $\mathrm{mm} ; m$ is the mass of the hammer, $\mathrm{kg}$. In the study the $F$ is $76.087 \mathrm{kN}$ and the $m$ is $135 \mathrm{~kg}$.

The bending strength is calculated based on Eq.(2):

$$
S=\frac{3 \times P \times l}{2 \times t^{2} \times W}
$$

where $S$ is the bending strength, MPa; $P$ is rupture force, $\mathrm{N} ; l$ is the span of the clamp, $\mathrm{mm} ; t$ is the height of compact, $\mathrm{mm} ; W$ is the width of compact, $\mathrm{mm}$. In the experiment the $l, t$ and $W$ were $25 \mathrm{~mm}, 3 \mathrm{~mm}$ and $6 \mathrm{~mm}$, respectively.

The tensile strength is calculated in accordance with Eq.(3):

$$
\sigma_{\mathrm{b}}=\frac{F_{\mathrm{b}}}{A_{0}}
$$


where $\sigma_{\mathrm{b}}$ is the tensile strength, MPa; $F_{\mathrm{b}}$ is the maximum force before rupture, $\mathrm{N} ; A_{0}$ is the cross-section area, $\mathrm{mm}^{2}$.

\section{Results and Discussion}

\subsection{Density analysis}

As the impact velocity rises up, green density increases gradually as shown in Fig.4. When the impact velocity is less than $9.5 \mathrm{~m} / \mathrm{s}$ it increases linearly with rising impact velocity. It increases from $7.095 \mathrm{~g} / \mathrm{cm}^{3}$ to $7.492 \mathrm{~g} / \mathrm{cm}^{3}$, at an average rate of

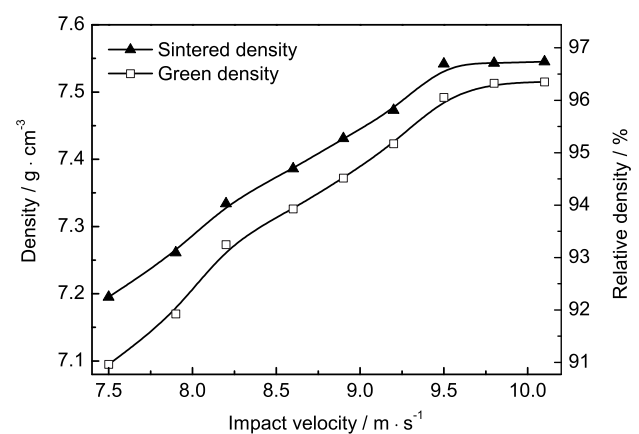

Fig.4 Curves of density vs impact velocity. $0.199 \mathrm{~g} \cdot \mathrm{cm}^{-3}$ per $\mathrm{m} \cdot \mathrm{s}^{-1}$, as the impact velocity increases from $7.5 \mathrm{~m} / \mathrm{s}$ to $9.5 \mathrm{~m} / \mathrm{s}$. But, it increases very slowly for the impact velocity above $9.5 \mathrm{~m} / \mathrm{s}$. It increases from $7.492 \mathrm{~g} / \mathrm{cm}^{3}$ to $7.515 \mathrm{~g} / \mathrm{cm}^{3}$, at an average rate of $0.038 \mathrm{~g} \cdot \mathrm{cm}^{-3}$ per $\mathrm{m} \cdot \mathrm{s}^{-1}$, as the impact velocity increases from $9.5 \mathrm{~m} / \mathrm{s}$ to $10.1 \mathrm{~m} / \mathrm{s}$. In particular, when the impact velocity increases from $9.8 \mathrm{~m} / \mathrm{s}$ to $10.1 \mathrm{~m} / \mathrm{s}$ the green density only increases $0.002 \mathrm{~g} / \mathrm{cm}^{3}$.

According to Fig.5, $7.513 \mathrm{~g} / \mathrm{cm}^{3}$ green body (Fig.5b) has tinier pores than $7.095 \mathrm{~g} / \mathrm{cm}^{3}$ one (Fig.5a), and the amount of pores is higher for $7.095 \mathrm{~g} / \mathrm{cm}^{3}$ material than for $7.513 \mathrm{~g} / \mathrm{cm}^{3}$ one. Higher impact velocity decreases the porosity from $9 \%$ to $4 \%$.

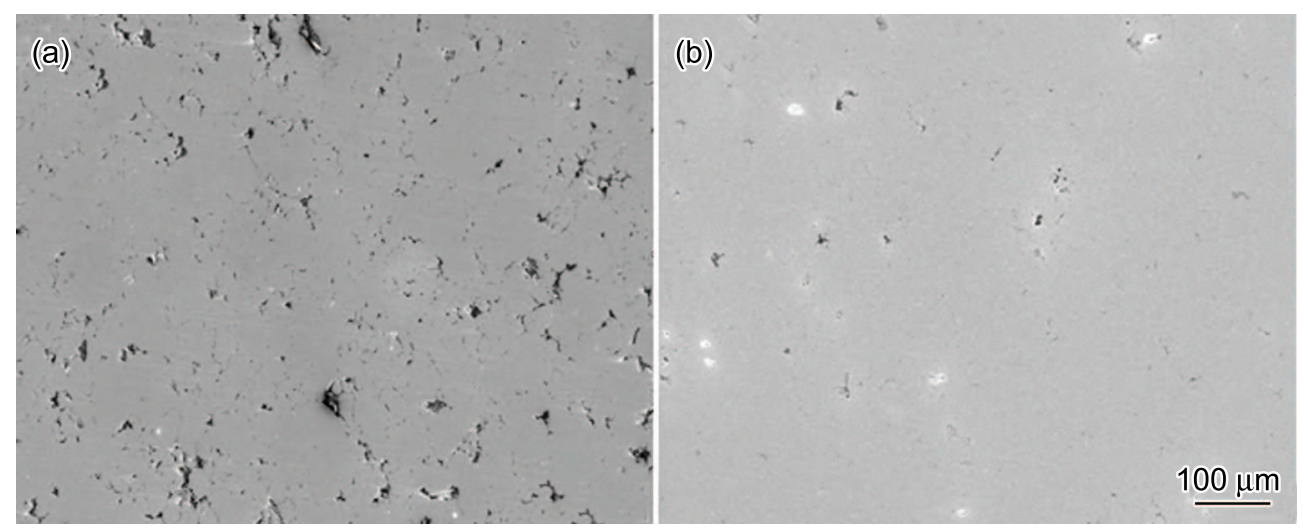

Fig.5 Cross-section SEM morphologies for the green densities of $7.095 \mathrm{~g} / \mathrm{cm}^{3}$ (a) and $7.513 \mathrm{~g} / \mathrm{cm}^{3}$ (b).

There are a lot of pores in powder body before compaction, so finer particles are easily filled into pores among coarser particles under impact force. Therefore, the green density is improved mainly in the form of sliding, filling pores and rearranging of powder particles when the impact velocity is lower. As the impact velocity increases, the impact force is increased gradually. Consequently, the capacity of powder particles to deform and fill pores is increased achieving higher green density. The intense deformation of powder particles will result in work hardening when the impact velocity is higher ${ }^{[12,13]}$, so it is difficult to achieve higher green density through further deformation of powder particles. As a result, the green density increases very slowly at the impact velocity above $9.8 \mathrm{~m} / \mathrm{s}$.

It also can be obtained from Fig. 4 that the rule of sintered density of part is similar to that of the green density and the maximal sintered density is about $7.545 \mathrm{~g} / \mathrm{cm}^{3}$. When the 
green density is less than $7.492 \mathrm{~g} / \mathrm{cm}^{3}$, the sintered density grows quickly, but it increases very slowly over the green density of $7.513 \mathrm{~g} / \mathrm{cm}^{3}$. Furthermore, as the impact velocity increases, the difference between the sintered density and the green density decreases gradually. In the initial stage of sintering the contacting area among powder particles will be improved gradually, then the sintering neck will be formed. In the later stage of sintering the phenomena of spheriodization, shrinkage and disappearance of pores of green compact appear resulting in volume shrinkage of sintered body. When the green density is lower, i.e. higher porosity, the shrinkage of specimen is obvious, so the sintered density increases quickly. However, as the green density rises up, the shrinkage of parts decreases slowly, then the increasing rate of sintered density decreases. Consequently, it is difficult to improve the sintered density through enhancing the green density which exceeds a certain value.

\subsection{Bending strength of green compact}

Fig.6 shows the relationship between the bending strength of green compact and the impact velocity. It is apparent that the bending strength increases gradually with the impact velocity increasing. Nevertheless, the curve exhibits two different stages. In the first stage the bending strength increases evidently when the impact velocity is less than $9.2 \mathrm{~m} / \mathrm{s}$. It increases from $50.98 \mathrm{MPa}$ to $59.83 \mathrm{MPa}$, at an average rate of $5.21 \mathrm{MPa}$ per $\mathrm{m} \cdot \mathrm{s}^{-1}$, when the impact velocity increases from $7.5 \mathrm{~m} / \mathrm{s}$ to $9.2 \mathrm{~m} / \mathrm{s}$. In the sec-

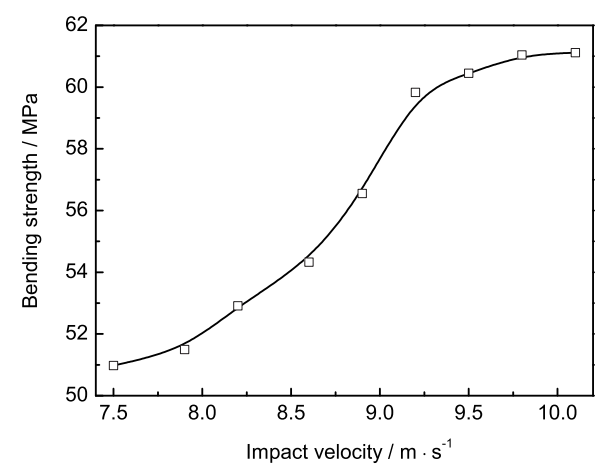

Fig.6 Bending strength of green compact vs impact velocity.

ond stage it only increases from $59.83 \mathrm{MPa}$ to $61.12 \mathrm{MPa}$, at an average rate of $1.43 \mathrm{MPa}$ per $\mathrm{m} \cdot \mathrm{s}^{-1}$, when impact velocity increases from $9.2 \mathrm{~m} / \mathrm{s}$ to $10.1 \mathrm{~m} / \mathrm{s}$. Of two periods the increasing rate of the second stage is about a quarter of that for the first one. In addition, the bending strength increases from $61.04 \mathrm{MPa}$ to $61.12 \mathrm{MPa}$, only increasing $0.08 \mathrm{MPa}$, when the impact velocity increases from $9.8 \mathrm{~m} / \mathrm{s}$ to $10.1 \mathrm{~m} / \mathrm{s}$.

As the impact velocity rises up, the impact force increases considerably, so this will cause continuously displacement and deformation of powder particles, leading to pores reducing and green density increasing. Therefore, the contacting area among particles increases gradually and improves the bonding force among particles resulting in green strength increasing. In addition, higher green strengths exhibited by most of the compacts made from irregular shaped powders are believed to be due in large measure to mechanical interlocking and cold welding ${ }^{[1]}$. Shear forces among particles expose clean surfaces which are then brought together with great impact force. Rapidity of the process prevents oxidation of these fresh surfaces before contact. Fig.7 appears the phenomena of cold welding and mechanical interlocking among powder particles. The position of arrows and the area of rectangle represent the cold welding and the mechanical interlocking, respectively.

\subsection{Tensile strength of compact after sintering}

As shown in Fig. 8 the tensile strength of sintered body increases slowly as the sintered 


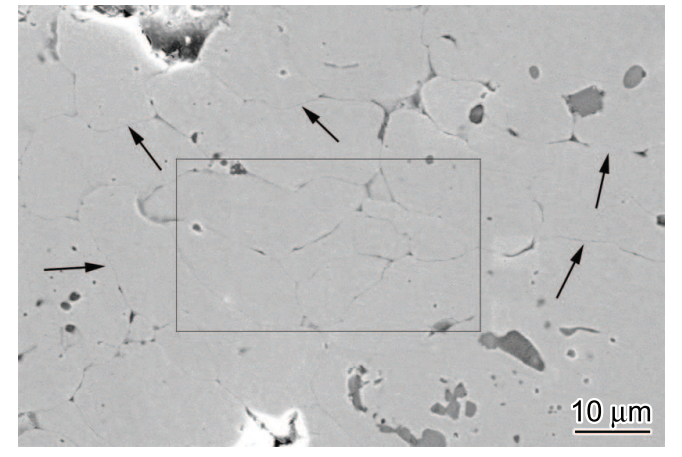

Fig.7 Cross-section SEM image at the impact velocity of $9.5 \mathrm{~m} / \mathrm{s}$, the position of arrows and the area of rectangle represent cold welding and mechanical interlocking, respectively.

density increases. The tensile strength increases from $145 \mathrm{MPa}$ to $190 \mathrm{MPa}$ when the sintered density increases from $7.195 \mathrm{~g} / \mathrm{cm}^{3}$ to $7.542 \mathrm{~g} / \mathrm{cm}^{3}$. The porosity affects obviously the mechanical properties of sintered body ${ }^{[14]}$. Lower sintered density leads to higher porosity, so the tensile strength is lower. As the sintered density rises up, the porosity deceases gradually, so the tensile strength increases continuously.

Fig.9 presents the fracture morphology of sintered body and it appears ductile rupture.

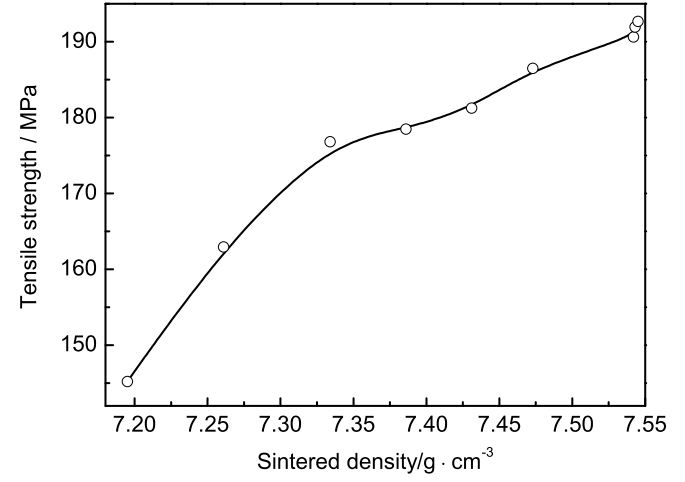

Fig.8 Curve of tensile strength of sintered body $v s$ sintered density.

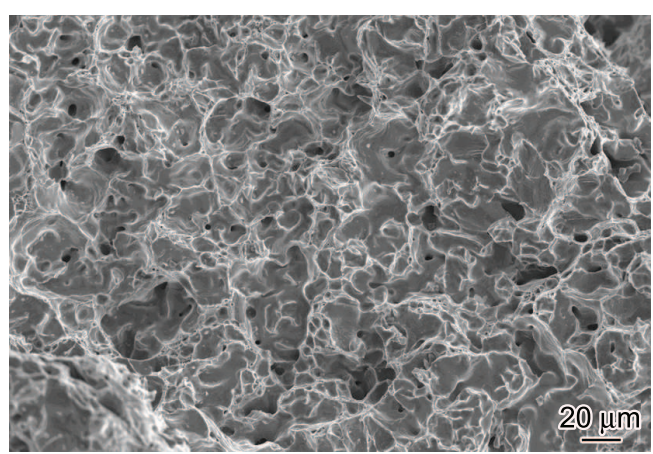

Fig.9 Fracture morphology of sintered body.

\section{Conclusions}

Density and mechanical properties of parts prepared using HVC are presented at the impact velocity from $7.5 \mathrm{~m} / \mathrm{s}$ to $10.1 \mathrm{~m} / \mathrm{s}$. The green density and the sintered density and the bending strength of green compacts increase gradually as the impact velocity increases. Furthermore, the tensile strength of sintered material is improved continuously with the sintered density enhancing. In the study, the sintered density of $7.545 \mathrm{~g} / \mathrm{cm}^{3}$ and the tensile strength of $190 \mathrm{MPa}$ are achieved at the optimal impact velocity of $9.8 \mathrm{~m} / \mathrm{s}$.

\footnotetext{
Acknowledgements - This study is financially supported by National 973 Program (No.2006CB605207), MOE Program for Changjiang Scholars and Innovative Research Team in University of China (No.I2P407).
}

\section{REFERENCES}

[1] J.W. Hagemeyer and J.A. Regalbuto, Int J Powder Metall 4 (1968) 18.

[2] P. Skoglund, M. Kejzelman and I. Hauer, Proc of the 2002 World Congress on Powder Metallurgy and Particulate Materials (Metal Powder Industries Federation, Orlando, USA, 2002).

[3] R.L. Orban, Romanian Reports in Physics 56 (2004) 505. 
[4] D. Souriou, P. Goeuriot, O. Bonnefoy, G. Thomas and F. Doré, Powder Technology 190 (2009) 152.

[5] P. Doremus, F. Duwa, P. Francois, G. Puente and C.H. Allibert, Proc of the 2002 World Congress on Powder Metallurgy and Particulate Materials (Metal Powder Industries Federation, Orlando, USA, 2002).

[6] J.Z. Wang, X.H. Qu, H.Q. Yin, S.Y. Zhou and M.J. Yi, Materials for Mechanical Engineering 32 (2008) 5 (in Chinese).

[7] A. Skagerstrand, Proc of the 2002 World Congress on Powder Metallurgy and Particulate Materials (Metal Powder Industries Federation, Orlando, USA, 2002).

[8] P. Jonsén, H.Å. Häggblad, L. Troive, J. Furuberg, S. Allroth and P. Skoglund, Mater Sci Forum 534-536 (2007) 289.

[9] P. Skoglund, Proc of the 2002 World Congress on Powder Metallurgy and Particulate Materials (Metal Powder Industries Federation, Orlando, USA, 2002).

[10] Y.Y. Li, T.L. Ngai, D.T. Zhang, Y. Long and W. Xia, J Mater Proc Technol 129 (2002) 354.

[11] D. Yarnton and T.J. Davies, Int J Powder Metall 8 (1972) 51.

[12] P.Y. Huang, Principles of Powder Metallurgy (Metallurgical Industry Press, Beijing, 1997) p.173 (in Chinese).

[13] C.Y. Wu and L.Y. Zhang, Mech Principles Powder Forming (Metallurgical Industry Press, Beijing, 2003) p.34 (in Chinese).

[14] Z.P. Zhou and X.P. Shen, Practical Technology of Machine Parts of Powder Metallurgy (Chemical Industries Press, Beijing, 2006) p.381 (in Chinese). 